\title{
Mortalidade por Acidentes de Transporte Terrestre no Brasil na última década: tendência e aglomerados de risco
}

\author{
Mortality due to Road Traffic Accidents in Brazil \\ in the last decade: trends and risk clusters
}

Otaliba Libânio de Morais Neto ${ }^{1}$

Marli de Mesquita Silva Montenegro ${ }^{2}$

Rosane Aparecida Monteiro ${ }^{3}$

João Bosco Siqueira Júnior ${ }^{4}$

Marta Maria Alves da Silva ${ }^{5}$

Cheila Marina de Lima ${ }^{5}$

Luiz Otávio Maciel Miranda ${ }^{5}$

Deborah Carvalho Malta ${ }^{6}$

Jarbas Barbosa da Silva Junior ${ }^{6}$

${ }^{1}$ Instituto de Patologia

Tropical e Saúde Pública, Universidade Federal de

Goiás. Rua Delenda Rezende

de Melo s/n, Setor

Universitário.

74605-050 Goiania GO.

otaliba.libanio@gmail.com

${ }^{2}$ Coordenação Geral de

Informação e Análise

Epidemiológica,

Departamento de Análise de

Situação de Saúde, Secretaria

de Vigilância em Saúde,

Ministério da Saúde.

${ }^{3}$ Departamento de Medicina

Social, Universidade de São

Paulo Ribeirão Preto.

${ }^{4}$ Instituto de Patologia

Tropical e Saúde Pública,

Universidade Federal de

Goiás.

${ }^{5}$ Coordenação Geral de

Doenças e Agravos não

Transmissíveis,

Departamento de Análise de

Situação de Saúde, Secretaria

de Vigilância em Saúde,

Ministério da Saúde.

${ }^{6}$ Secretaria de Vigilância em

Saúde, Ministério da Saúde.
Abstract Objective: To analyze the temporal trends of mortality due to Road Traffic Accidents (RTA) as well as identify the existence and location of high risk death clusters for RTA using spatial analysis. Methodology. Descriptive study of temporal trends by RTA, pedestrians, motorcyclists, motorists and passengers and spatial analysis for 2000 and 2010. The data was obtained from the Mortality Information System, and standardized rates were calculated by age in Brazilian states and municipalities grouped by population size. $R \boldsymbol{e}$ sults: The mortality rates due to RTA between 2000 and 2010 varied from 18 to 22.5 deaths/ 100,000 inhabitants. The risk of death for pedestrians decreased in recent years, though motorists, motorcyclists and passengers saw a rising trend. A higher risk of death by RTA occurred in municipalities with populations up to 20,000 inhabitants and in those from 20,000 to 100,000 inhabitants. Spatial analysis revealed risk clusters for RTA and motorcyclists and pillion riders with an increase between 2000 and 2010 and enlargement of the areas most at risk in the Northeast. Conclusion: Increase in the rates of mortality by RTA mostly in the Northeast. Coordinated action between government, civil society and the citizens themselves is required to tackle this problem.

Key words Traffic accident, Trends, Motorcycles, Vehicles, Cluster analysis.
Resumo Objetivo: Analisar a tendência temporal da mortalidade por Acidentes de Transporte Terrestre (ATT) e identificar a existência e a localização de aglomerados de alto risco de mortes por ATT. Metodologia: Estudo descritivo de tendência da mortalidade por ATT, pedestre, ocupante de motocicleta e de veículo, de 2000 a 2010 e análise espacial para 2000 e 2010. Os dados foram obtidos do Sistema de Informações sobre Mortalidade; calcularam-se as taxas padronizadas por idade, para Unidades Federadas (UF) e municípios por porte populacional. Resultados: A taxa de mortalidade por ATT entre 2000 e 2010 variou de 18 para 22,5 óbitos/100 mil habitantes. O risco de morte para pedestre reduziu, os de ocupantes de veículos e de motocicletas apresentaram crescimento. O maior risco de morte por ATT ocorreu nos municípios com até 20 mil habitantes e nos de 20 a 100 mil. A análise espacial mostrou os aglomerados de risco para ATT e para ocupantes de motocicletas com aumento destes entre 2000 e 2010 e ampliação das áreas com maior risco na região Nordeste. Conclusão: Aumento das taxas de mortalidade por ATT principalmente na região Nordeste. Faz-se necessário uma atuação coordenada do governo, da sociedade civil e dos próprios cidadãos no enfretamento desta realidade.

Palavras-chave Acidente de trânsito, Tendências, Motocicletas, Veículos, Análise de clusters 


\section{Introdução}

Em março de 2010 a Organização das Nações Unidas (ONU) proclamou o período 2011 a 2020 como a Década de Ação pela Segurança no Trânsito e instou os países a atingirem a meta de estabilizar e de reduzir as mortes causadas pelo trânsito $^{1}$ por meio da implementação de um plano de ação voltado para cinco pilares de intervenção: fortalecimento da gestão, investimento em infraestrutura viária, segurança veicular, comportamento e segurança dos usuários do trânsito e atendimento pré-hospitalar e hospitalar ao trauma ${ }^{2}$.

O esforço das Nações Unidas e da Organização Mundial da Saúde (OMS) justifica-se pelo crescente número de vítimas de trânsito. Anualmente são 1,3 milhões de mortes e entre 20 e 50 milhões de pessoas lesionadas, concentrados nos países de média e baixa renda ${ }^{3}$. Esses países possuem $84,5 \%$ da população mundial, $47,9 \%$ da frota de veículos e $91,5 \%$ das mortes causadas pelo trânsito. Já os de alta renda têm $52,1 \%$ da frota de veículos e respondem por apenas $8,5 \%$ das mortes ${ }^{4}$.

A previsão da OMS é de que em 2020 o número de óbitos atinja 2,3 milhões e seja a sexta causa de morte em todo mundo, cifras puxadas pelos países menos desenvolvidos. Pois, ao contrário, nos países de alta renda prevê-se um declínio dos óbitos em torno de $27 \%$ entre 2010 e 2020. Na América Latina a previsão é de que haja uma elevação de 154 mil mortes em 2010, para 180 mil em 2020, elevação de $48 \%{ }^{3}$.

Van Beeck et al. ${ }^{5}$ estudando a mortalidade no trânsito nos países mais industrializados identificaram o seguinte padrão: durante o crescimento econômico há aumento da frota de veículos e das taxas de mortalidade; uma vez estabilizado, o crescimento econômico persiste, mas ocorre uma inversão da tendência da mortalidade, mesmo com o aumento da frota de veículos ${ }^{5}$. Os custos estimados com esses agravos em todo mundo, segundo a OMS, chega a 1\%, 1,5\% e $2 \%$ do Produto Nacional Bruto dos países de baixa, média e alta renda, respectivamente ${ }^{3}$.

O Brasil ocupa o $5^{\circ}$ lugar entre os países com maior número de mortes no trânsito, precedido pela Índia, China, EUA e Rússia ${ }^{4}$. O número de óbitos por Acidente de Transporte Terrestre (ATT) no Brasil em 2009 foi de 37.635, sendo a primeira subcausa dentro do grupo das causas externas para as faixas etárias de 10 a 14 anos e 40 a 59 anos. Nas demais, é a segunda causa de morte. A taxa de mortalidade por acidente de transporte terrestre no país em 2009 foi de 19,6 óbitos por cem mil habitantes, sendo de 32,6 para homens e 7,1 para mulheres. Observando-se as grandes regiões do país, as taxas mais elevadas ocorreram nas regiões Centro-Oeste e Sul com valores de 29,0 e 25,4 por cem mil habitantes, respectivamente ${ }^{6}$.

Em 2010, houve 145.920 internações de vítimas de acidentes no trânsito, nos hospitais financiados pelo Sistema Único de Saúde (SUS), com custo aproximado de 187 milhões de reais. Os homens representaram 78,3\% dos hospitalizados e as mulheres, $21,7 \%{ }^{6}$.

Segundo pesquisas realizadas pelo Instituto de Pesquisas Econômicas Aplicadas (IPEA) ${ }^{7}$ os custos anuais dos acidentes de trânsito nas rodovias estaduais, municipais e federais do Brasil, em 2005, foi de 22 bilhões de reais. Estudo anterior (2003) estimou em 5,3 bilhões de reais o custo anual dos acidentes de trânsito nas áreas urbanas do país ${ }^{8}$.

Este estudo visa analisar a tendência dos ATT entre os anos de 2000 e 2010 nas unidades federadas e nos municípios brasileiros, bem como identificar a existência e localização de aglomerados de alto risco de mortes por essa causa, utilizando análise espacial.

\section{Método}

Estudo exploratório de tendência da mortalidade por ATT no Brasil, no período de 2000 a 2010 e estudo de análise espacial de identificação de aglomerados de risco para ATT nos municípios brasileiros nos anos de 2000 e 2010.

A fonte de dados foi a Declaração de Óbito, documento base do Sistema de Informações sobre Mortalidade (SIM). As mortes por ATT foram selecionadas segundo a Classificação Estatística Internacional de Doenças e Problemas Relacionados à Saúde (Décima Revisão) CID-10, sob os códigos de V01 a V89, quando analisados em sua totalidade, posteriormente, subdivididos nas seguintes categorias, de acordo com a condição da vítima: Pedestre (V01 a V09), Ocupante de Motocicleta (V20 a V29) e Ocupante de veículo (V40 a V79) ${ }^{9}$. Esta última categoria engloba acidentes com automóvel, caminhonete, veículo de transporte pesado (veículos de carga segundo o Código de Trânsito Brasileiro) e ônibus.

Os arquivos do SIM, referentes aos anos de 2000 a 2010 foram obtidos do Departamento de Análise de Situação de Saúde da Secretaria de Vigilância em Saúde. E foram utilizadas as seguintes variáveis: município de residência, idade e sexo. 
As informações sobre a população total, por sexo e idade, foram as do Instituto Brasileiro de Geografia e Estatística (IBGE), disponibilizadas pelo Departamento de Informática do Sistema Único de Saúde (Datasus). Para os anos de 2000 e 2010, usaram-se os dados dos censos demográficos. Para os demais, produziram-se estimativas com projeções intercensitárias ${ }^{10}$. Para os anos intercensitários foi utilizado o método de calculo de interpolação aritmética.

Os municípios foram categorizados em 4 categorias de porte populacional: até 20.000, de 20.001 até 100.000 , de 100.001 até 500.000 e mais de 500.000 habitantes.

Foram construídas as taxas de mortalidade para os ATT (todas as condições de vítimas) e para pedestres, ocupantes de veículos e ocupantes de motocicletas. Foram calculadas as variações percentuais das taxas entre os anos de 2000 e 2010. Para os estados com alto subregistro de óbitos e com pequenos números de óbitos e grandes flutuações das taxas entre os anos, essas variações percentuais não foram consideradas na análise e nos resultados do estudo.

Para a análise espacial com a finalidade de identificação de aglomerados de mortalidade por ATT utilizou-se o programa SaTScan ${ }^{\mathrm{TM}}$ versão 9.1.1 $1^{11-12}$ que tem como uma das suas funcionalidades a identificação de padrão espacial de uma doença ou agravo de saúde num determinado território. Trabalhou-se com a análise espacial pura, usando-se o modelo probabilístico de Poisson discreto para encontrar os aglomerados no território. Utilizouse dois critérios como parâmetro para o tamanho máximo de um aglomerado: um raio de 300 quilômetros e 50\% da população sob risco de morte por ATT.

\section{Resultados}

Entre os anos de 2000 e 2010, a população brasileira variou de 169.799 .170 para 190.755 .799 habitantes o que representou um aumento de $11 \%$ no período. A variação da frota de veículos foi de 29.722.950 para 64.817.974 veículos, ou seja, um aumento de $54 \%$ no período. Os óbitos por ATT elevaram-se de 28.995 para 42.844 , um aumento de $32,3 \%$ na década.

\section{Tendência da Mortalidade por ATT no Brasil segundo a Condição da Vítima}

A taxa de mortalidade por ATT variou de 18,2 por 100 mil habitantes em 2000 para 22,54 óbitos em 2010, um aumento de 22,54\% (Figura 1). Já a razão de óbitos em relação à frota de veículos teve uma redução de 47,6\% variando de 9,8 óbitos por 10 mil veículos, em 2000, para 6,6, em 2010.

A análise da tendência segundo a condição das vítimas mostra mudanças importantes no período: os pedestres, que apresentavam o maior risco entre 2000 e 2007, declinaram nos anos subsequentes. Os ocupantes de veículos apresentaram tendência crescente em todo o período; e os ocupantes de motocicletas que mostravam as menores taxas no início da série, tiveram forte tendência de aumento e em 2010 ultrapassaram as demais (Figura 1b).

\section{Mortalidade por Acidentes de Trânsito nas Unidades Federadas}

A mortalidade por ATT nos estados brasileiros e no Distrito Federal no período apresentaram as seguintes características: os estados com menores taxas foram Bahia e Maranhão em 2000 (ambos com 10,1 óbitos/100.000 hab.) e o Amazonas em 2010 (15,6 óbitos/100.000 hab.). As maiores taxas foram em Roraima em 2000 (38,5 óbitos/100.000 hab.) e Rondônia em 2010 (39,9 óbitos/100.000 hab.), conforme mostra a Tabela 1.

(a) Todas as vítimas

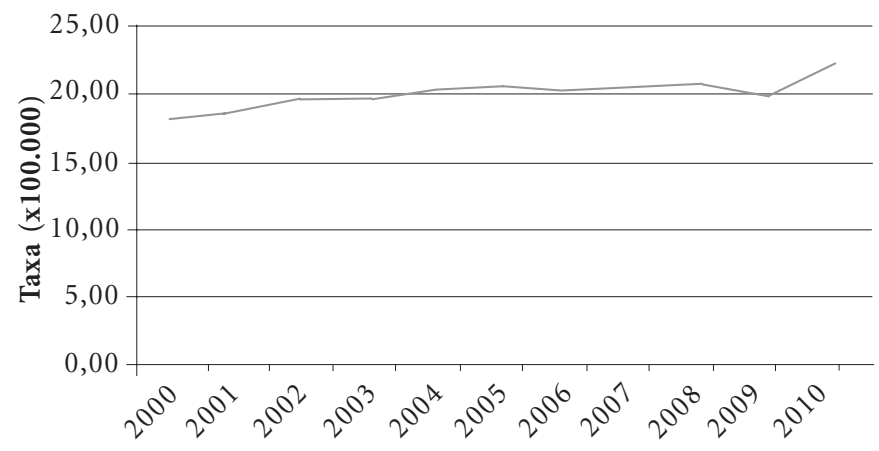

Ano

Figura 1a. Taxa padronizada de mortalidade por acidentes de transporte terrestre. Todas as vítimas. Brasil, 2000 a 2010.

Fonte: SIM/SVS/MS. 


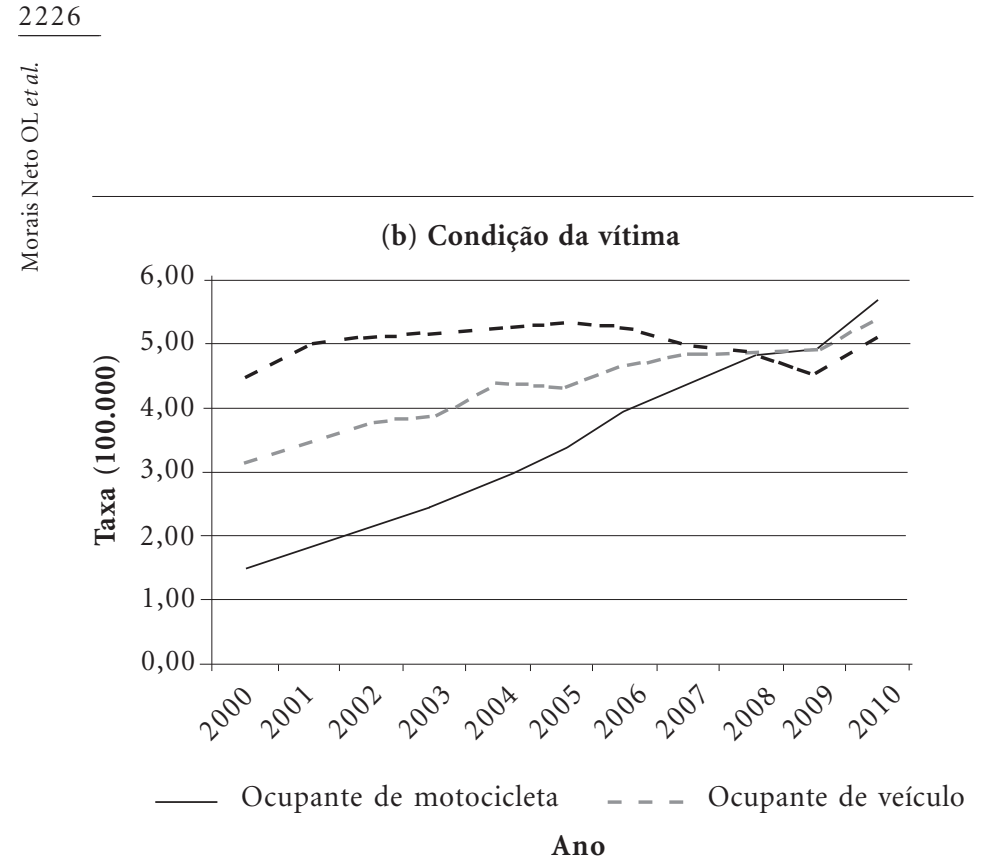

Figura 1b. Taxa padronizada de mortalidade por acidentes de transporte terrestre segundo a condição da vítima. Brasil. 2000 a 2010.

Fonte: SIM/SVS/MS.

Tabela 1. Taxa de mortalidade por acidentes de transporte terrestre (todas as vítimas) e ordem de posição das taxas no ano de 2000, segundo as Unidades Federadas (UF), 2000 e 2010.

\begin{tabular}{|c|c|c|c|c|}
\hline \multirow[b]{2}{*}{ Unidade Federada } & \multicolumn{2}{|c|}{2000} & \multicolumn{2}{|c|}{2010} \\
\hline & ATT Total & Posição & ATT Total & Posição \\
\hline Roraima & 38,5 & 1 & 37,9 & 3 \\
\hline Mato Grosso & 29,3 & 2 & 36,3 & 4 \\
\hline Goiás & 29,0 & 3 & 33,3 & 5 \\
\hline Santa Catarina & 28,9 & 4 & 29,2 & 11 \\
\hline Espírito Santo & 28,1 & 5 & 31,1 & 9 \\
\hline Paraná & 27,8 & 6 & 32,2 & 6 \\
\hline Distrito Federal & 27,6 & 7 & 21,9 & 17 \\
\hline Tocantins & 27,3 & 8 & 38,1 & 2 \\
\hline Rondônia & 26,9 & 9 & 39,9 & 1 \\
\hline Amapá & 24,2 & 10 & 21,0 & 18 \\
\hline Alagoas & 22,4 & 11 & 27,1 & 12 \\
\hline Sergipe & 21,1 & 12 & 31,0 & 10 \\
\hline Pernambuco & 20,9 & 13 & 23,2 & 14 \\
\hline Mato Grosso do Sul & 20,9 & 14 & 31,1 & 8 \\
\hline Acre & 19,5 & 15 & 21,0 & 19 \\
\hline Rio Grande do Sul & 19,2 & 16 & 20,7 & 21 \\
\hline Ceará & 18,9 & 17 & 25,2 & 13 \\
\hline Rio de Janeiro & 18,3 & 18 & 17,5 & 25 \\
\hline Rio Grande do Norte & 18,1 & 19 & 20,6 & 22 \\
\hline São Paulo & 16,2 & 20 & 17,2 & 26 \\
\hline Piauí & 16,1 & 21 & 32,2 & 7 \\
\hline Amazonas & 13,8 & 22 & 15,6 & 27 \\
\hline Paraíba & 13,4 & 23 & 23,0 & 15 \\
\hline Minas Gerais & 13,4 & 24 & 20,8 & 20 \\
\hline Pará & 12,5 & 25 & 18,7 & 23 \\
\hline Maranhão & 10,1 & 26 & 22,2 & 16 \\
\hline Bahia & 10,1 & 27 & 18,7 & 24 \\
\hline
\end{tabular}

Fonte: SIM/SVS/MS.
O ranking das taxas de mortalidade por ATT para os anos de 2000 e 2010 mostrou mudanças importantes no risco de morte. As taxas foram agrupadas em três grupos no período: os que permaneceram estáveis, os que tiveram aumento e os que diminuíram o risco de mortalidade.

Alguns estados que já em 2000 estavam entre os seis com as taxas mais elevadas e em 2010 não alteraram ou pouco modificaram sua posição no ranking foram: Paraná, Roraima, Mato Grosso, Goiás e Espírito Santo (Tabela 1). Os que pioraram a sua posição entre 2000 e 2010 foram: Piauí passou da $21^{a}$ posição para a 7a; Maranhão passou da 26a para a 16a; Paraíba, da 23a para 15a; Mato Grosso do Sul, da $14^{\text {a }}$ para a $8^{\mathrm{a}}$ posição; Tocantins, da $8^{a}$ para a segunda; e Rondônia assumiu o primeiro lugar, apresentando as taxas mais elevadas em 2010.

Reduziram as taxas de mortalidade no período: Distrito Federal, que passou da $7^{\text {a }}$ posição para a 17a (27,6 óbitos para 21,9/100.000); Amapá que melhorou oito posições (de 24,2 óbitos para 21,0); Rio de Janeiro que melhorou sete posições passando de 18,3 óbitos para 17,5; Santa Catarina que passou do $4^{\circ}$ lugar em 2000 para a $11^{\text {a }}$ em 2010; e São Paulo que melhorou seis posições (Tabela 1).

Entre os anos de 2000 e 2010 nas Unidades da Federação houve redução nos riscos de morte no Distrito Federal $(25,8 \%)$, no Amapá $(15,2 \%)$ e no Rio de Janeiro $(4,6 \%)$. Nos demais houve elevação, com destaque para os estados da região Nordeste. Os que mais aumentaram foram: Maranhão (54,5\%), Piauí (50,1\%), Bahia (46,0\%), Paraíba $(41,7 \%)$. No Sudeste: Minas Gerais (35,6\%); No Centro Oeste: Mato Grosso do Sul $(33,0 \%)$; e no Norte: Pará $(32,9 \%)$, Rondônia $(32,7 \%)$ e Tocantins $(28,4 \%)$ (Figura 2a).

Para os pedestres o perfil de variação dos riscos entre 2000 e 2010 mostra uma tendência de redução na maioria dos estados. Mas os estados de Sergipe, Pará, Mato Grosso do Sul, Maranhão, Piaú, Bahia e Rondônia tiveram elevação acima de $10 \%$ nesse período (Figura $2 \mathrm{~b}$ ).

Apresentaram aumento nos riscos de acidentes e mortes para os ocupantes de veículos os estados do Rio de Janeiro, Rio Grande do Sul, Maranhão, Minas Gerais, São Paulo, Mato Grosso do Sul e Piauí. No Piauí esse aumento foi de $91 \%$. Já o Distrito Federal teve uma redução de $72 \%$ (Figura 2c).

Com relação aos motociclistas, observou-se aumento das taxas de morte entre 2000 e 2010 em todas as Unidades Federadas, exceto no Acre, que foi excluído dessa análise por grandes varia- 
(a) Todas as vítimas

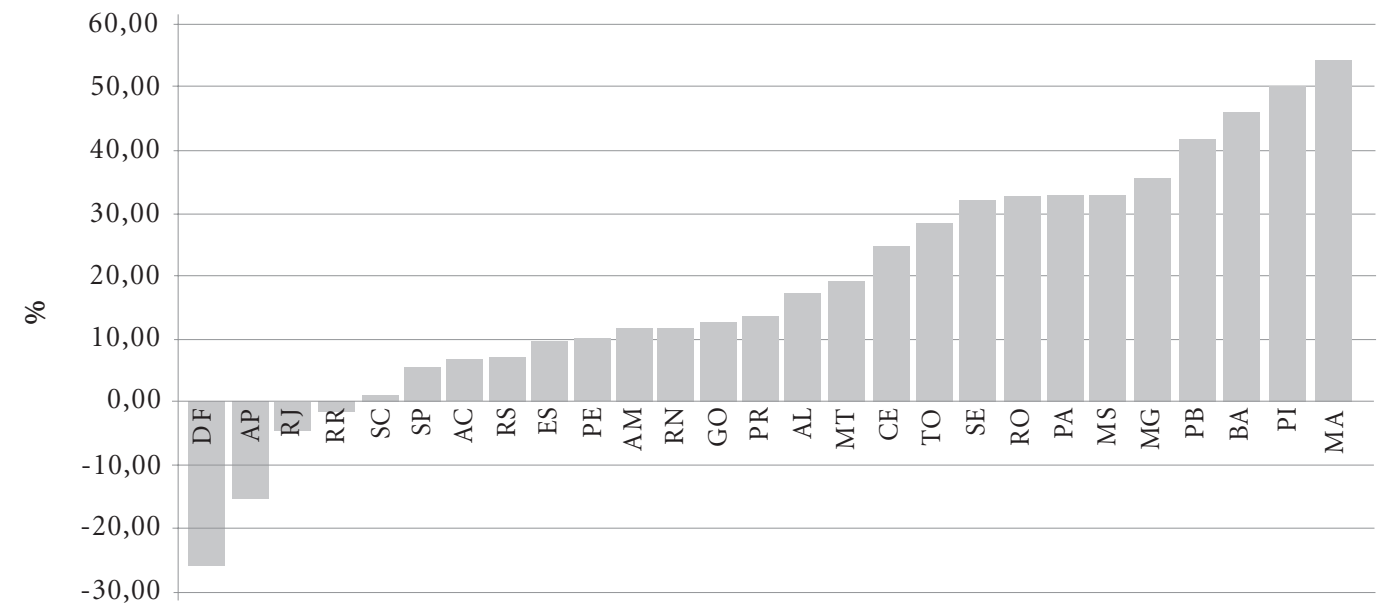

Unidade Federada

Figura 2a. Variação percentual da taxa de mortalidade por ATT (todas as vítimas) nas Unidades Federadas entre os anos de 2000 e 2010.

Fonte: SIM/SVS/MS.

(b) Ocupante de motocicleta

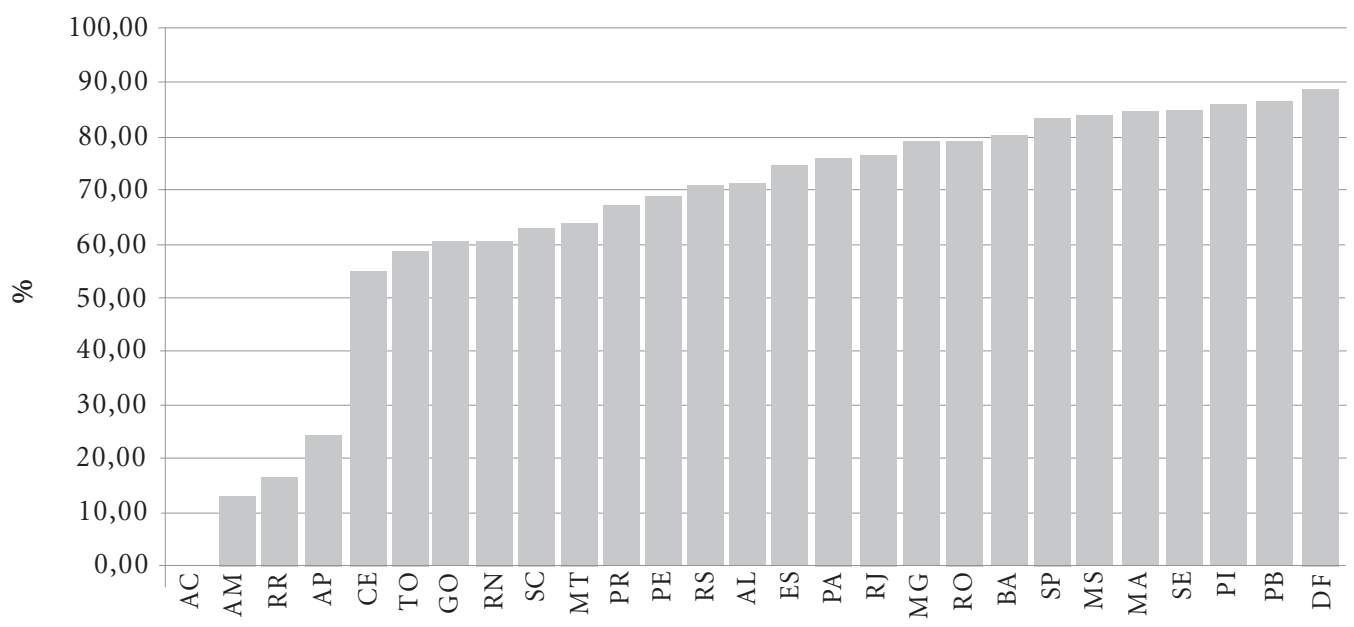

Unidade Federada

Figura 2b. Variação percentual da taxa de mortalidade por ATT (ocupante de motocicleta) nas Unidades Federadas entre os anos de 2000 e 2010.

Fonte: SIM/SVS/MS. 
ções no período estudado, baixa cobertura do Sistema de Informações sobre Mortalidade e ao pequeno número de óbitos registrados no ano. Sete estados tiveram aumento na taxa superior a $80 \%$ e, em dezesseis estados, aumento entre $50 \%$ a 79\% (Figura 2d).

\section{Risco de Mortalidade por ATT em Municípios agrupados segundo Porte Populacional}

As taxas de mortalidade por ATT nos agregados de municípios categorizados segundo os portes populacionais no ano de 2000 variaram

(c) Pedestres

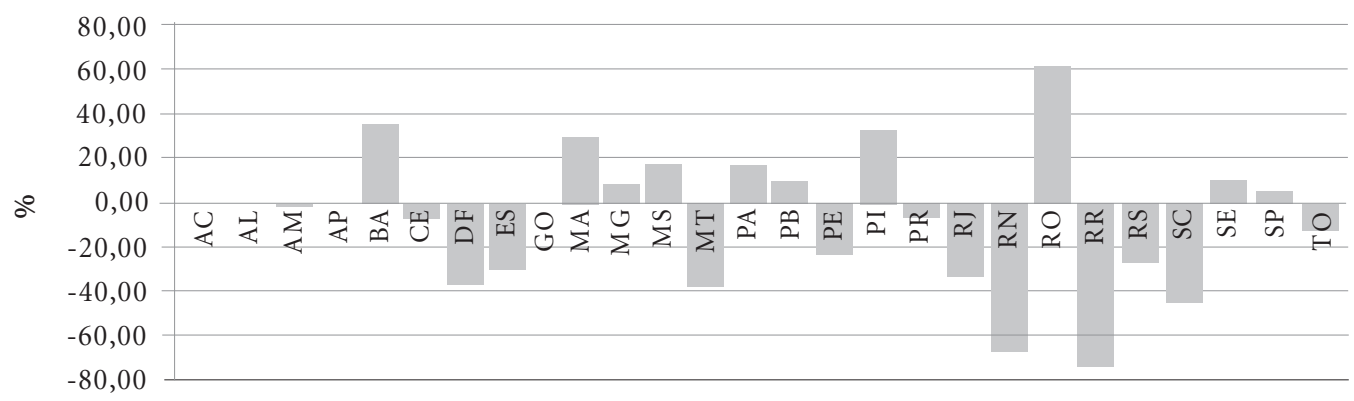

\section{Unidade Federada}

Figura 2c. Variação percentual da taxa de mortalidade por ATT (pedestres) nas Unidades Federadas entre os anos de 2000 e 2010.

Fonte: SIM/SVS/MS.

(d) Ocupante de veículo

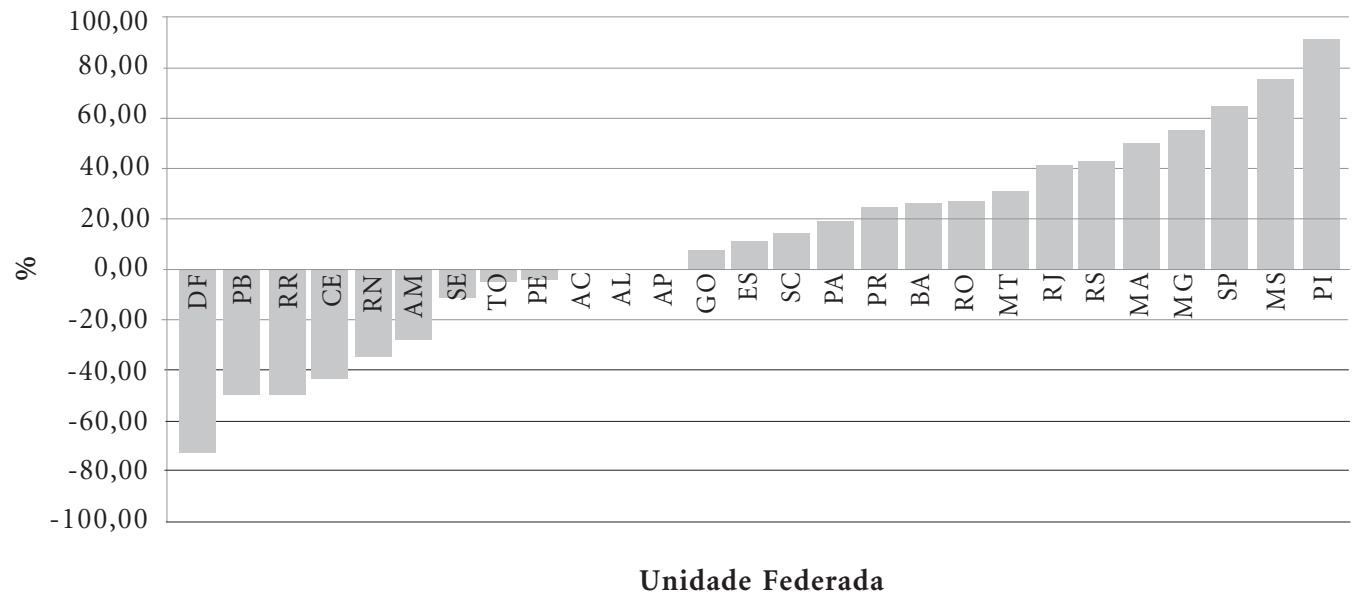

Figura 2d. Variação percentual da taxa de mortalidade por ATT (ocupante de veículo) nas Unidades Federadas entre os anos de 2000 e 2010.

Fonte: SIM/SVS/MS. 
de 15,4 óbitos/100.000 hab. nos de 500 mil habitantes ou mais e 20,9 nos de 100 a 500 mil. No ano de 2010, a menor taxa permaneceu nos municípios acima de 500 mil (17,0 por 100 mil habitantes) e a mais elevada foi observada nos de pequeno porte, com menos de 20 mil habitantes (26,1 por 100 mil habitantes).

A análise por condição da vítima mostrou o seguinte perfil nos anos de 2000 e 2010: para ocupantes de motocicletas e de veículos, em 2000, as maiores taxas ocorreram nos municípios de 20 a 100 mil habitantes e em 2010, nos com menos de 20 mil. Os municípios com mais de 500 mil habitantes apresentaram as menores taxas no período. Para os pedestres, as maiores taxas foram observadas nos municípios de 100 a 500 mil habitantes em 2000 e nos de 500 mil e mais habitantes em 2010. As menores taxas ocorreram nos municípios com menos de 20 mil habitantes no período.

A análise da variação percentual das taxas padronizadas por acidentes de trânsito segundo o porte populacional dos municípios e os tipos de vítimas, entre os anos de 2000 e 2010 mostrou os seguintes resultados: o risco de morte por ATT (todas as vítimas) apresentou maior elevação nos municípios com até 20 mil habitantes e nos de 20 a 100 mil habitantes, com variação percentual de $35,7 \%$ e $24,6 \%$, respectivamente. Para motociclistas, a maior elevação foi de 79,4\% nos municípios com mais de 500 mil habitantes e de 77,4\% nos menores de 20 mil habitantes. Para os ocupantes de automóveis, observou-se elevação das taxas em $38,0 \%$ e $31,5 \%$ nos municípios até 20 mil habitantes e acima de 500 mil habitantes, respectivamente. Para pedestres houve redução das taxas de mortalidade entre 2000 e 2010 nas quatro categorias de porte populacional (Figura 3).

\section{Identificação de aglomerados de risco de mortes por ATT nos Municípios}

Realizou-se uma análise espacial para identificação de aglomerados de risco de morte por ATT (todas as condições de vítimas) e para ocupantes de motocicletas.

\section{Por todos os tipos de vítimas}

No ano de 2000 foram identificados 13 aglomerados de risco em todo país constituídos por 1.956 municípios com população de 52 milhões de habitantes e 12.763 óbitos por ATT (Figura 4a).

O aglomerado de maior risco é constituído por um grande número de municípios do Paraná, Santa Catarina e alguns de São Paulo que fazem fronteira com o Paraná. Esse aglomerado

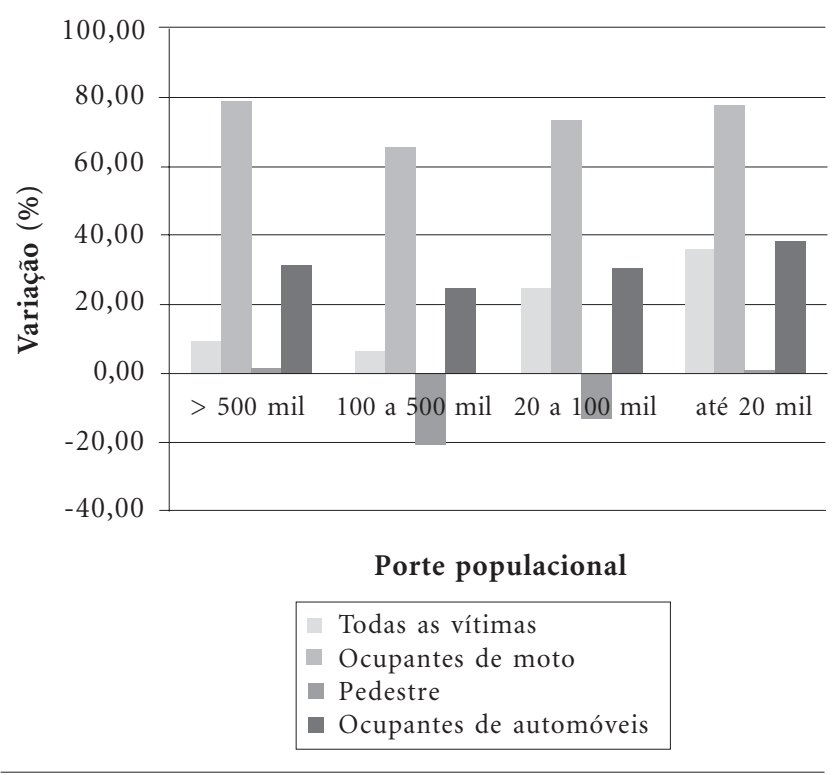

Figura 3. Variação percentual das taxas padronizadas de ATT entre 2000 e 2010 segundo o porte populacional dos municípios e o tipo de vítima.

Fonte: SIM/SVS/MS.

é formado por 474 municípios e população de 12.356.353 habitantes. Houve 3.388 óbitos observados, enquanto o número de óbitos esperados a partir do modelo de Poison foi de 2.124,8. O risco relativo foi 1,67 , estatisticamente significativo $(\mathrm{p}<0,0001)$ e a taxa de mortalidade, $27,4 /$ 100.000 habitantes.

Os outros 12 aglomerados estatisticamente significativos distribuíram-se nas demais regiões do país. Na região Nordeste: um que congrega 146 municípios de Alagoas e Pernambuco, com população de 4.664 .451 habitantes, 1005 óbitos e taxa de mortalidade de 21,5/100.000 habitantes.

Na região Norte: um em Roraima, formado por três municípios, com população de 220.386 habitantes, 98 óbitos e taxa de mortalidade de 44,4/ 100.000 mil habitantes. Um em Rondônia, formado apenas pelo município de Porto Velho, com 105 óbitos e taxa de 31,3/100.000. E um formado por 68 municípios localizados na fronteira entre os estados do Tocantins, Pará e Mato Grosso, com população de 823.265 habitantes, 222 óbitos e taxa de 26,9/100.000 habitantes.

No Centro-Oeste foram observados dois aglomerados em Mato Grosso: um no norte do esta- 
do, formado por 25 municípios, e outro no centro sul com 58 municípios. Um no estado de Goiás formado por 210 municípios que abarcam quase todo o estado, todo o Distrito Federal, alguns municípios de Minas Gerais da região do Triângulo Mineiro e municípios de Mato Grosso, com 1.805 óbitos e taxa de 25,7 por 100 mil habitantes.

No Sudeste observaram-se: um aglomerado formado por 200 municípios localizados na região de fronteira entre Espírito Santo, Rio de Janeiro e Minas Gerais, com 1.438 óbitos e taxa de 24,4/100.000 habitantes; um mais ao sul que congrega 227 municípios localizados na fronteira entre Minas Gerais, São Paulo e Rio de Janeiro, com 532 óbitos e taxa de 22/100.000 habitantes; e outro que reúne 200 municípios do sul de Minas Gerais e Norte de São Paulo, com população de 9.951.504 habitantes, 2.084 de óbitos e taxa de 20,9/100.000 habitantes.

Na região Sul, além do aglomerado principal já descrito, encontraram-se outros dois: um na fronteira entre o Paraná, São Paulo e Mato Grosso do Sul, com 149 municípios, população de 2.595.594 habitantes, 696 óbitos e taxa de 26,8/ 100.000; e outro no centro-norte do Rio Grande do Sul formado por 227 municípios, população de 3.831.066 habitantes, 830 óbitos e taxa de 21,6/ 100.000 habitantes.

No ano de 2010, persistia como aglomerado principal a mesma região já citada para o ano 2000 e que reúne municípios do Paraná, Santa Catarina, alguns de São Paulo e do norte do Rio Grande do Sul. Entre 2000 e 2010 houve aumento de 474 para 632 no número de municípios qe passaram a compor o aglomerado. Houve aumento também na taxa de mortalidade, que elevou-se de 27,4 para 30,3 óbitos por 100 mil habitantes.

Os dados de 2010 também mostraram mudanças importantes na região Nordeste que passou a apresentar três aglomerados: o primeiro formado por 222 municípios concentrados nos estados do Piauí e Ceará, com 1.392 óbitos e taxa de mortalidade de 27,2/100.000 habitantes; o segundo, com 61 municípios dos estados do Ceará, Rio Grande do Norte e alguns da Paraíba, com 297 óbitos e taxa de 29,1; o terceiro, que reúne 166 municípios de Sergipe e Alagoas, com 1.030 óbitos e taxa de 25,0/100.000 habitantes.

No Norte, não foi observado o aglomerado de Roraima que existia em 2000. No entanto, o de Rondônia foi expandido para 38 municípios agregando um de Mato Grosso, com um total de 441 óbitos e taxa de 34,4/100.000 habitantes. Houve expansão do aglomerado formado por municí- pios na fronteira entre Pará, Tocantins, Maranhão e Mato Grosso que passou a reunir 109 municípios, 649 óbitos e taxa de 32,7/100.000 habitantes.

No Centro-Oeste, observaram-se as seguintes mudanças: expansão do aglomerado formado principalmente por municípios de Goiás, que passou de 210 para 229 municípios, as taxas subiram de 25,7 para 30,5/100.000 habitantes e houve a exclusão do Distrito Federal, que em 2000 fazia parte do conjunto; surgimento de um aglomerado formado por 59 municípios dos estados de Goiás, Mato Grosso e Tocantins, com 191 óbitos e taxa de mortalidade de 35,0/100.000 habitantes; expansão do número de municípios de Mato Grosso do Sul no aglomerado formado por municípios da fronteira entre Mato Grosso do Sul, Paraná e São Paulo com 90 municípios, 687 óbitos e taxa de 30,5/100.000 habitantes.

No Sudeste, desapareceu o aglomerado na fronteira entre Minas e São Paulo e o que existia no litoral norte de São Paulo e fazia divisa com Rio de Janeiro. Observou-se também a redução do número de municípios de São Paulo no aglomerado principal, já citado, e a formação de um de menor dimensão, composto por 26 municípios na fronteira sudeste entre São Paulo e Paraná.

No Sul, houve a expansão dos municípios do aglomerado principal abarcando até unidades do norte do Rio grande do Sul e o desaparecimento do aglomerado constituído apenas por municípios do Rio Grande do Sul.

\section{Por ocupantes de motocicletas}

No ano de 2000, foram observados 10 aglomerados em todo país, constituídos por 1.020 municípios (18,5\% de todos os municípios do país), com uma população de 25.422.029 habitantes ( $15 \%$ de toda população do país) e um total de 1.010 óbitos ( $46 \%$ de todos os ocorridos no país) de ocupantes de motocicletas.

O aglomerado principal foi formado por 340 municípios do Ceará e Piauí e, em menor número, do Rio Grande do Norte, Paraíba e Pernambuco com população de pouco mais de nove milhões de habitantes. Houve 326 óbitos com uma taxa de mortalidade de 3,5/100.000 (Figura 4b).

$\mathrm{Na}$ região Nordeste, além do aglomerado principal, foi observado um segundo, formado por 30 municípios de Pernambuco, com população total de 970 mil habitantes, 46 óbitos e taxa de 4,7/100.000 (Figura 4b).

No Norte, encontraram-se três aglomerados. Um em Roraima, formado por 10 municípios, 290 mil habitantes, 43 óbitos e a taxa mais elevada do país: 14,8/100.000. O segundo é formado por 65 
municípios do Pará e Tocantins, com população de 1.190.302 habitantes, 63 óbitos e taxa de mortalidade de 5,3/100.000. O terceiro, formado por 49 municípios de Tocantins e um do Mato Grosso, tem população de 568 mil habitantes, 26 óbitos e taxa de 4,6/100.000 habitantes (Figura 4b).

a. Aglomerados de alto risco ATT (todos os meios de transporte)

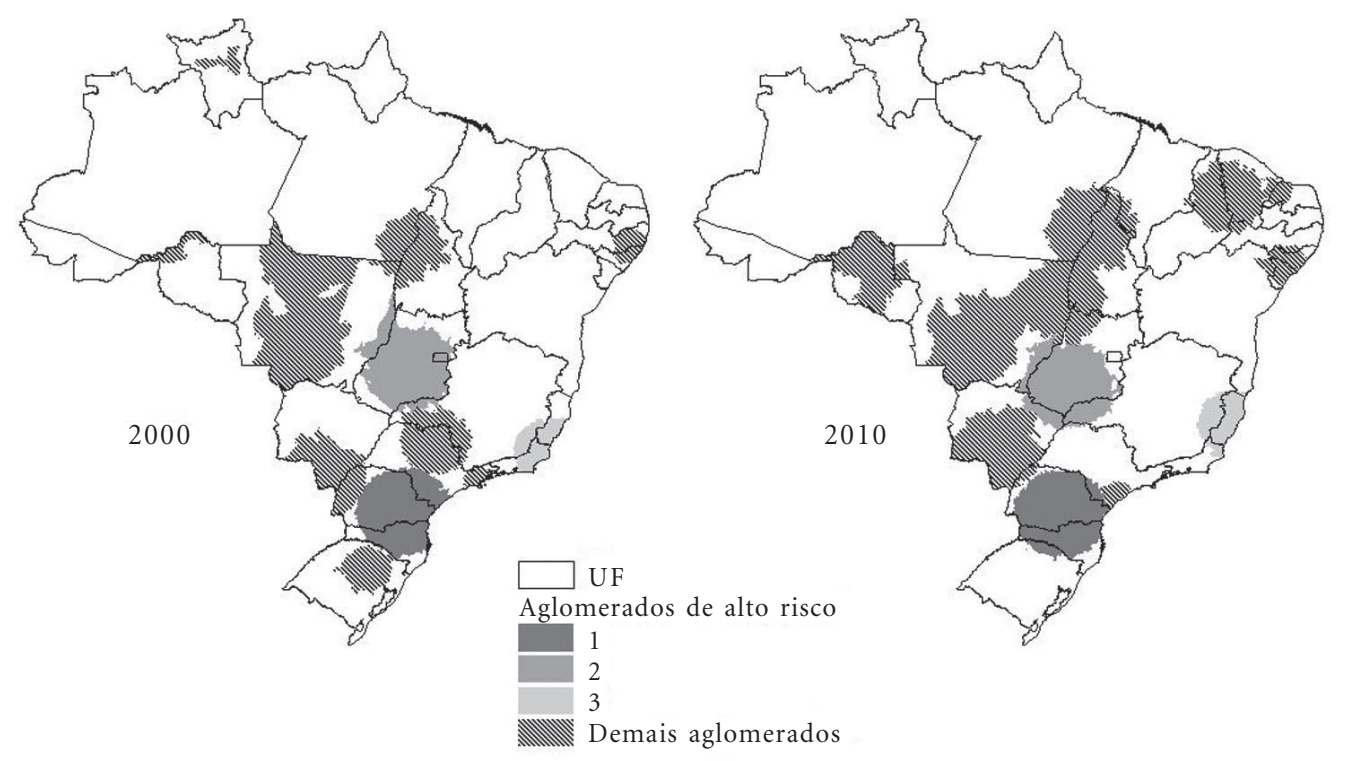

b. Aglomerados de alto risco ATT (motocicletas)

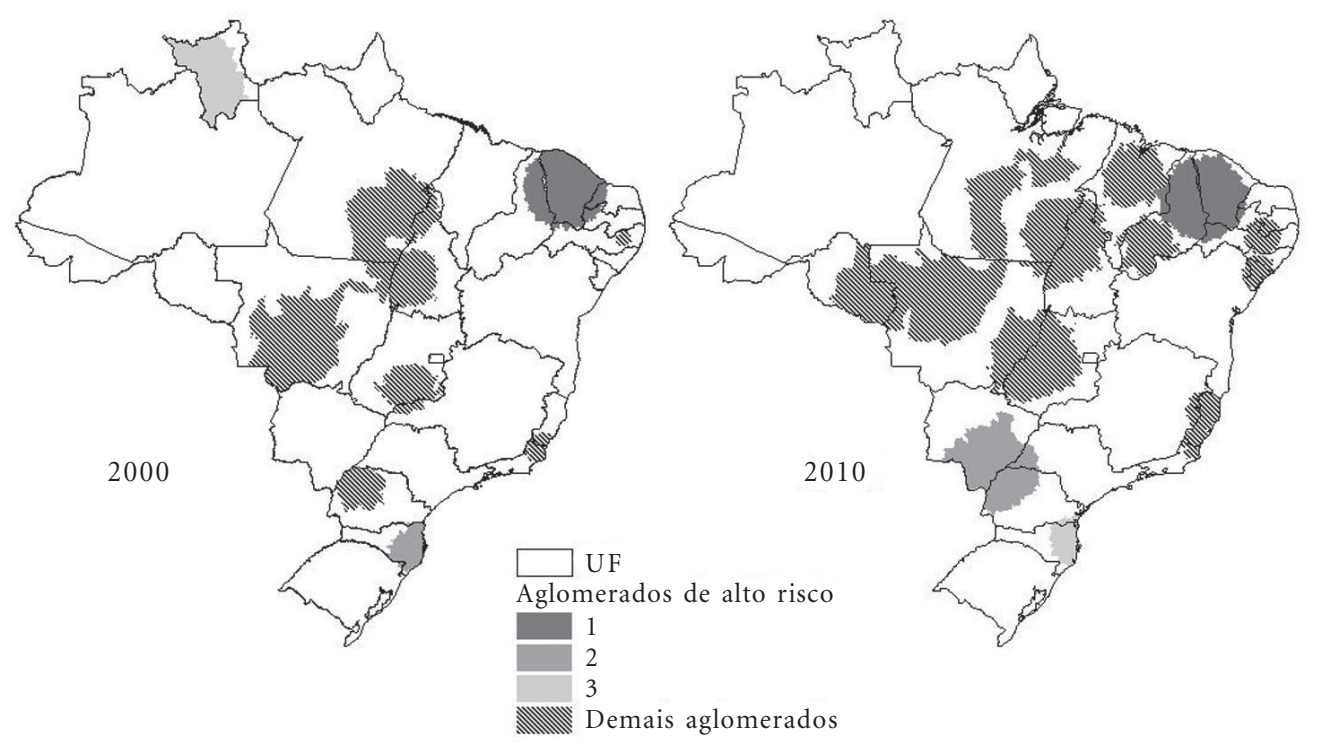

Figura 4. Aglomerados de alto risco para mortalidade por ATT nos municípios brasileiros. 2000 e 2010. (a) ATT por todas as condições de vítimas; (b) ocupantes de motocicletas. 
No Centro-Oeste, observaram-se dois aglomerados. Um em Mato Grosso, com 58 municípios, 1.629.835 habitantes, 57 óbitos e taxa de 3,5/100.000 habitantes. O segundo, com $101 \mathrm{mu}$ nicípios concentrados em Goiás e alguns em Minas Gerais, com 3.142.307 habitantes, 109 óbitos e taxa de 5,3/100.000 habitantes (Figura 4b).

No Sudeste foi identificado apenas um aglomerado formado por 40 municípios na região sul do Espírito Santo e norte do Rio de Janeiro, com população de 1.338.212 habitantes, 59 óbitos e taxa de 4,4/100.000 habitantes (Figura 4b).

No Sul, observaram-se dois aglomerados. Um na região oeste do Paraná, com 179 municípios, população de 3,2 milhões de habitantes, 125 óbitos e taxa de 3,9/100.000 habitantes. O segundo, na região leste de Santa Catarina, formado por 148 municípios, 3,8 milhões de habitantes, 156 óbitos e taxa de 4,0/100.000 habitantes (Figura 4b).

Em 2010, o número de aglomerados aumentou de 10 para 14 e o número de municípios que os conformavam cresceu de 1.020 para 1.674 , que representavam 30\% dos municípios brasileiros, $20,3 \%$ da população e $40,8 \%$ do total de óbitos de ocupantes de motos. A mediana das taxas de mortalidade nos aglomerados que era de 4,2/ 100.000 habitantes em 2000, passou a $10,5 /$ 100.000 em 2010.

$\mathrm{O}$ aglomerado principal se manteve na mesma região com oito municípios a mais, concentrados no Piauí. O número de óbitos, no entanto, aumentou de 326 para 845 e a taxa de mortalidade passou de 3,5 para 11,4/100.000 habitantes (Figura 4b).

Nas cinco regiões, as principais mudanças na conformação dos aglomerados ocorreram conforme descrito a seguir. No Nordeste, observaram-se três movimentos: aumento do número de municípios nos aglomerados, aumento do número de aglomerados e elevação nas taxas de mortalidade. No aglomerado principal foi observado aumento de municípios, dos óbitos e das taxas. No que em 2000 abarcava apenas municípios de Pernambuco houve aumento do número nesse estado e expansão para os da Paraíba e de Alagoas. Nesse conjunto a taxa de mortalidade aumentou de 4,7 para 8,7/100.000 habitantes. Observaram-se três novos aglomerados: um no sul do Piauí, com 50 municípios, 50 óbitos e taxa de 14/100.000; um segundo no Maranhão com 114 municípios, 03 milhões de habitantes e taxa de mortalidade de 6,9/100.000; e um terceiro, formado por 110 municípios de Alagoas, Sergipe e alguns da Bahia, com população de 2,9 milhões de habitantes, 301 óbitos e taxa de mortalidade de 10,3/100.000 habitantes (Figura 4b).

No Norte, desapareceu o aglomerado de Roraima, foi observado um novo com 11 municípios, 530 mil habitantes e 59 óbitos e taxa de mortalidade de 11,1/100.000 no Pará; e outro novo em Rondônia e Mato Grosso, com 42 municípios, 882 mil habitantes, 94 óbitos e taxa de mortalidade de 10,7/100.000 habitantes (Figura 4b).

No Centro-Oeste, também houve mudanças. Em Mato Grosso, no ano 2000, os aglomerados se concentravam da região centro-sul. Em 2010, encontraram-se dois no centro-norte do estado junto com o de Rondônia; e na região leste do estado, junto com o formado por municípios de Goiás. No Mato Grosso do Sul, observou-se um na região sudeste do estado em confluência com municípios do oeste do Paraná e sudoeste de São Paulo, formado por 296 municípios, 551 óbitos e taxa de 8,6/100.000 habitantes (Figura 4b).

No Sudeste, em 2010, observou-se ampliação do aglomerado formado por municípios do Espírito Santo, Rio de Janeiro e Minas Gerais e uma expansão do número de municípios da região oeste de São Paulo no aglomerado da fronteira com o Paraná e Mato Grosso do Sul (Figura $4 \mathrm{~b})$.

No Sul, persistiram em 2010, dois aglomerados existentes em 2000: o do oeste do Paraná descrito acima; e o da região leste de Santa Catarina. Esse último teve redução no número de municípios de 148 para 139, porém, aumento de óbitos (156 para 425) e da taxa de mortalidade (4,0 para 9,5/100.000 habitantes) (Figura 4b).

\section{Discussão}

Os resultados do artigo permitem conhecer o comportamento da mortalidade por ATT no Brasil no período de 2000 a 2010 mostrando uma situação preocupante de elevação do número de óbitos e das taxas de mortalidade causadas pelo trânsito no país, decorrente, principalmente, do crescimento das taxas de mortalidade envolvendo os ocupantes de veículos e de motocicletas, na região Nordeste e nos municípios de pequeno porte populacional.

O principal limite do estudo está relacionado à utilização das bases de dados secundários oriundos das declarações de óbito, documento base do SIM. Como descrito na publicação Saúde Brasil $2010^{6}$ do Ministério da Saúde, há uma melhoria da cobertura do SIM, bem como no registro da causa básica da morte. No entanto, 
há ainda baixa cobertura nos estados da região Norte e Nordeste do país em proporções que variam de 76,5\% no estado do Maranhão a 93,2\% em Pernambuco6 ${ }^{6}$ Especificamente para os óbitos por causas externas (capítulo XX da CID-10) observa-se um elevado número de mortes por ATT codificadas na categoria violência de intenção indeterminada (Y10 a Y34), principalmente, entre 2006 a 2009. Para o ano de 2010 houve empenho dos estados no sentido de fazer a correção da causa básica de morte no SIM, por meio da investigação nos registros da segurança pública, e em alguns casos com o registro dos órgãos de trânsito, fazendo com que os dados para este ano sejam mais qualificados e com menor percentual de óbitos codificados como de intenção indeterminada.

Houve tendência de elevação de 22,5\% na taxa de mortalidade por ATT entre os anos de 2000 e 2010. Em 2000 a taxa era de 18,2; em 2004 elevase para 20,3 e em 2010, a taxa aumentou mais ainda, atingindo o valor de 22,3 óbitos por 100.000 habitantes. A taxa de mortalidade no Brasil é elevada, quando comparada à taxa média da região das Américas que é de 15,8 por 100.000 habitantes e é superior à dos países de alta e média renda das Américas que estão em patamares de 13 e 17 por 100.000 habitantes, respectivamente ${ }^{4}$. Porém a taxa do país é inferior à do México que é de 23 por 100.000 habitantes ${ }^{13}$. Esta elevação na tendência das taxas no Brasil nos últimos anos é contrária ao que vem sendo observado na tendência da mortalidade por ATT nos países de alta renda como Austrália, França, Japão, Suécia, Canadá e Estados Unidos 4 .

A elevação da taxa de mortalidade no período analisado é coerente com os estudos de Mascarenhas et al. ${ }^{14}$ que observaram aumento de 14,9\% entre 2000 e 2009 e Bacchieri e Barros ${ }^{15}$ que encontraram 19\% de acréscimo entre 1998 e 2008. Sugere-se que o aumento observado entre 2009 e 2010 se deve, principalmente, à melhoria da qualidade do registro da causa básica de morte no banco de dados do SIM no ano de 2010, uma vez que houve redução dos óbitos por causas externas de intenção indeterminada (CID-10 Y10 a Y34) nesse ano. Entretanto, outros fatores devem ser considerados, como aumento da frota, deficiência na fiscalização, precariedade de transporte público, infraestrutura, dentre outros.

Os dados descritos no presente estudo mostraram a tendência decrescente das mortes no trânsito envolvendo os pedestres e o aumento das mortes de ocupantes de veículos e ocupantes de motocicletas. Este último grupo, no ano de
2010, assumiu, pela primeira vez, o maior risco de morte entre todas as vítimas do trânsito com 5,7 óbitos por 100.000 habitantes com forte tendência ascendente, como observado por outros autores $^{16-19}$.

Com relação ao perfil da mortalidade por ATT por Unidades Federadas ressaltam-se os seguintes pontos: (i) os estados do Nordeste foram os que mais aumentaram as taxas de mortalidade entre 2000 e 2010 com variação percentual da ordem de $55 \%$ e $50 \%$ de elevação nos estados do Maranhão e Piauí, respectivamente. Em estudos anteriores, os estados da região Nordeste apresentavam taxas mais reduzidas em relação aos das demais regiões. Mas, em 2010, Piauí e Sergipe estão entre os dez estados brasileiros com taxas mais elevadas; (ii) em relação à condição da vítima, ressalta-se o aumento das taxas de morte de ocupantes de motocicletas em todos os estados, sendo que, em sete deles o aumento foi superior a $80 \%$, com destaque para o Piauí, Paraíba e o Distrito Federal. Outro resultado importante foi a redução das mortes de pedestres em quase todos os estados.

Nos municípios houve grande elevação das taxas de mortalidade entre os anos 2000 e 2010 para os ocupantes de motocicletas e de outros veículos. A maior elevação do número e das taxas de óbitos ocorreu com ocupantes de motocicletas, e as maiores variações percentuais aconteceram nos municípios de grande porte - acima de 500 mil habitantes - e nos de pequeno porte - com menos de 20 mil. Estudos confirmam o aumento nos municípios de porte acima de 500 mil habitantes, Montenegro et al. ${ }^{16}$ apontaram crescimento da taxa de mortalidade entre motociclistas (homens) no Distrito Federal de 36,2\% ao ano e Marín Léon et al. ${ }^{17}$ mostram que em Campinas a proporção de óbitos por acidentes com ocupantes de motocicleta em relação ao total de óbitos por ATT passou de 6,6\% para 49,3\% de 1995 para 2008 .

A análise espacial identificou aglomerados de risco para os óbitos de ATT e para os ocupantes de motocicletas nos anos de 2000 e 2010, possibilitando a identificação dos municípios que conformam as áreas geográficas de maior risco de acidente em cada período, bem como a mudança do padrão espacial de sua ocorrência, durante uma década. Para uma melhor compreensão da dinâmica dos acidentes de trânsito, a dimensão espacial nos estudos é uma importante ferramenta, indicando áreas prioritárias para intervenção. Souza et al. ${ }^{20}$ explicam a relevância da espacialização dos acidentes de trânsito por fornecer subsídios para o planejamento e a execução de polí- 
ticas públicas, aumentando sua eficácia e eficiência na redução e na prevenção desses agravos.

Iniciativas no Brasil para enfrentar a alta carga de mortes no trânsito vêm sendo implementadas de forma mais incisiva a partir de 1998 com a efetivação do Código de Trânsito Brasileiro ${ }^{21}$, que proporcionou uma redução importante da taxa de mortalidade após a sua entrada em vigor. Outra iniciativa foi a Lei $11.705^{22}$, denominada Lei "Seca", que entrou em vigor em junho de 2008 com impacto imediato na mudança do comportamento da população em relação à associação bebida e direção e redução das internações hospitalares e dos óbitos ${ }^{23}$, porém sem um efeito continuado, exceto em Unidades Federadas, como por exemplo, o Distrito Federal que vem reduzindo a taxa de mortalidade de forma contínua ao longo do período analisado.

Entretanto, é vital que as ações sejam contínuas e rigorosas, assim como a fiscalização ${ }^{23}$. Medidas educacionais são importantes e bastante utilizadas, porém não são efetivas quando utilizadas isoladamente ${ }^{24}$. Melhorias no transporte coletivo, investimento em modos de transporte alternativos e saudáveis, como a bicicleta, e incentivo para a utilização racional do automóvel são fundamentais para aumentar a qualidade de vida nas cidades e reduzir o número de acidentes ${ }^{15}$.

O Ministério da Saúde (MS) vem assumindo liderança nas ações de vigilância e prevenção de lesões e mortes provocadas pelo trânsito e de promoção da saúde e cultura de paz por meio das Políticas Nacionais de "Redução da Morbimortalidade por Acidentes e Violência" (Portaria GM/MS no 737, de 16/05/2001) ${ }^{25}$ e a de "Promoção à Saúde" (Portaria GM/MS no 687, de 30/03/2006) ${ }^{26}$. Essas políticas são fomentadas nos estados e municípios através da "Rede Nacional de Prevenção de Violências e Promoção da Saúde" (Portaria do Gabinete do Ministro da Saúde no 936, de 18/05/2004) ${ }^{27}$.

Dentre as várias ações desenvolvidas, destacam-se aquelas relacionadas ao "Projeto de Redução da Morbimortalidade por Acidentes de Trânsito - Mobilizando a sociedade e promovendo a saúde" (Portaria do Gabinete do Ministro da Saúde no 344, de 19/02/2002) 28, que foi implantado em 2002 em cinco cidades e que vem se expandindo para outras cidades a partir do apoio técnico e financiamento do MS. Outra iniciativa refere-se às ações de vigilância e monitoramento dos fatores de risco e proteção em relação às violências e aos acidentes com análise sobre morbidade e mortalidade, destacando-se o Projeto de "Vigilância de Violências e Acidentes (VIVA)" implantado no SUS em 2006 29-32.

Além disso, e como desdobramentos dessas políticas, o MS vem apoiando os estados e os municípios, financeira e tecnicamente para a estruturação da capacidade para implementação de intervenções de vigilância e prevenção de lesões e mortes causadas pelo trânsito com base em evidências $^{33}$ além do advocacy em relação à segurança viária e promoção de uma cultura de paz no trânsito. Exemplo mais recente é o Projeto Vida no Trânsito, coordenado pelo MS, e parte de um projeto maior denominado Segurança no Trânsito em Dez Países $^{34}$ (RS10), que tem como objetivo subsidiar gestores no fortalecimento de políticas de prevenção de lesões e mortes no trânsito por meio da qualificação das informações, planejamento, monitoramento, acompanhamento e avaliação das intervenções que são voltadas prioritariamente para dois fatores de risco: velocidade excessiva e inadequada e associação entre álcool e direção. $\mathrm{O}$ objetivo final do projeto é atingir metas de redução dos mortos e feridos graves causados pelo trânsito nas cidades onde o projeto encontra-se em andamento.

No atual cenário de crescimento da renda da população e de rápido aumento da frota nacional de veículos, com destaque para as motocicle$\operatorname{tas}^{16,17}$, associado à tendência crescente da mortalidade conforme resultados deste estudo, apontam para uma complexidade cada vez maior da realidade de segurança no trânsito no país. Não são suficientes os esforços individualizados de um único setor do governo.

O cenário é de desafio e exige uma ação coordenada de Governo nas três esferas, atuando de forma articulada com a sociedade civil para o enfrentamento do problema. Só assim o Brasil terá condições de cumprir as metas propostas pela ONU, da Década de Ação pela Segurança no Trânsito de 2011 a 2020. 


\section{Colaboradores}

OL Morais Neto, MMS Montenegro, RA Monteiro, JB Siqueira Júnior, MMA Silva, CM Lima, LOM Miranda, DC Malta e JB Silva Júnior participaram igualmente de todas as etapas de elaboração do artigo.

\section{Referências}

1. Organização das Nações Unidas (ONU). Assembleia Geral das Nações Unidas. [acessado 2012 abr 30]. Disponível em: http://daccess-dds-ny.un.org/doc/ UNDOC/LTD/N10/251/10/PDF/N1025110.pdf?Open Element

2. World Health Organization (WHO). United Nations Road Collaboration. [acessado 2012 abr 30]. Disponível em: http://www.who.int/roadsafety/decade_of _action/plan/plan_en.pdf.

3. World Health Organization (WHO). Mejoramiento de la seguridad vial en el mundo. [acessado 2012 abr 30]. Disponível em: http://www.who.int/roadsafety/ about/resolutions/sept_2011_sg_report_es.pdf.

4. World Health Organization (WHO). Global status report on road safety: time for action. Geneva: WHO; 2009. [acessado 2012 abr 30]. Disponível em: http:/ /www.who.int/violence_injury_prevention/road_ safety_status/2009.

5. Van Beeck EF, Borsboom GJ, Mackenbach JP. Economic development and traffic accident mortality in industrialized world, 1962-1990. Int J Epidemiol 2000; 29(3):503-509.

6. Brasil. Ministério da Saúde (MS). Secretaria de Vigilância em Saúde. Departamento de Análise de Situação em Saúde. Saúde Brasil 2010: Uma análise da situação de saúde e de evidências selecionadas de impacto de ações de vigilância em saúde. Brasília: MS; 2011.

7. Instituto de Pesquisa Econômica Aplicada (Ipea). Impactos Sociais e Econômicos dos Acidentes de Trânsito nas Rodovias Brasileiras. Brasília: Ipea; 2006.

8. Instituto de Pesquisa Econômica Aplicada (Ipea). Impactos sociais e econômicos dos acidentes de trânsito nas aglomerações urbanas. Brasília: Ipea; 2003.

9. Organização Mundial da Saúde (OMS). Classificação Estatística Internacional de Doenças e Problemas relacionados à Saúde. 10a Revisão. São Paulo: Editora da Universidade de São Paulo; 1994.

10. Brasil. Ministério da Saúde (MS). Informações de Saúde. [página na Internet]. [acessado 2012 maio 30]. Disponível em: http://tabnet.datasus.gov.br/cgi/ ibge/popdescr.htm\#origem

11. Kulldorff M. A spatial scan statistic. New York: Communications in Statistics: theory and Methods. 1997; 26:1481-1496.

12. Kulldorff M. SaTScan TM v9.1.1. Software for the spatial and space time scan statistics. Information Management Services Inc.; 2009. [acessado 2012 abr 30]. Disponível em: http://www.satscan.org/.

13. Híjar M, Chandran A, Pérez-Núñez R, Lunnen JC, Martín Rodríguez-Hernández J, Hyder AA. Quantifying the underestimated burden of road traffic mortality in Mexico: a comparison of three approaches. Traffic Inj Prev. 2012; 13(Supl. 1):5-10.

14. Mascarenhas MDM, Monteiro RA, Sá NNB, Gonzaga LAA, Neves ACM, Roza DL, MMA Silva, EC Duarte, DC Malta. Epidemiologia das causas externas no Brasil: mortalidade por acidentes e violências no período de 2000 a 2009. In: Mascarenhas MDM, Monteiro RA, Sá NNB, Gonzaga LAA, Neves ACM, Roza DL, MMA Silva, EC Duarte, DC Malta. Saúde Brasil 2010. Brasília: Editora Ministério da Saúde; 2011. p. 225-249. 
15. Bacchieri G, Barros AJD. Acidentes de trânsito no Brasil de 1998 a 2010: muitas mudanças e poucos resultados. Rev Saude Publica 2011; 45(5):949-963.

16. Montenegro MMS, Duarte EC, Prado RR, Nascimento AF. Mortalidade de motociclistas em acidentes de transporte no Distrito Federal, 1996 a 2007. Rev Saude Publica 2011; 5(3):529-538.

17. Marín-León L, Belon AP, Barros MBA, Almeida SDM, Restitutti MC. Tendência dos acidentes de trânsito em Campinas, São Paulo, Brasil: importância crescente dos motociclistas. Cad Saude Publica 2012; 28(1):39-51.

18. Bastos YGL, Andrade SM, Soares DA. Características dos acidentes de trânsito e das vítimas atendidas em serviço pré-hospitalar em cidade do Sul do Brasil, 1997/2000. Cad Saude Publica 2005; 21(3):815-822.

19. Barros AJ, Amaral RL, Oliveira MS, Lima SC, Goncalves EV. Acidentes de trânsito com vítimas: subregistro, caracterização e letalidade. Cad Saude Publica. 2003; 19(4):979-986.

20. Souza VR, Cavenaghi S, Alves JED, Magalhães MAFM. Análise espacial dos acidentes de trânsito com vítimas fatais: comparação entre o local de residência e de ocorrência do acidente no Rio de Janeiro. Rev Bras Estud Popul 2008; 25(2):353-364.

21. Brasil. Lei 9.503, de 23 de setembro de 1997. Código de Trânsito Brasileiro. Diário Oficial da União 1997; 24 set.

22. Brasil. Lei 11.705 , de 19 de junho de 2008. Altera a Lei no 9.503, de 23 de setembro de 1997, que 'institui o Código de Trânsito Brasileiro', e a Lei no 9.294 , de 15 de julho de 1996, que dispõe sobre as restrições ao uso e à propaganda de produtos fumígeros, bebidas alcoólicas, medicamentos, terapias e defensivos agrícolas, nos termos do $\$ 4$ o do art. 220 da Constituição Federal, para inibir o consumo de bebida alcoólica por condutor de veículo automotor, e dá outras providências. Diário Oficial da União 2008; 20 jun.

23. Mello Jorge MHP, Koizumi MS. Acidentes de trânsito causando vítimas: possível reflexo da lei seca nas internações hospitalares. Rev Abramet 2009; 27 (1):16-25.

24. Vasconcelos EA. O custo social da motocicleta no Brasil. Rev Transportes Publicos ANTP 2008; 30/31: 127-142.

25. Brasil. Ministério da Saúde (MS). Portaria GM/MS $n^{\circ} 737$, de 16/05/2001 - publicada no DOU no 96, Seção 1E de 18/05/2011, que institui a Política Nacional de Redução da Morbimortalidade por Acidentes e Violências. 2a Edição. Brasília (DF): MS; 2005. (Série E - Legislação de Saúde)
26. Brasil. Ministério da Saúde (MS). Portaria GM/MS $n^{\circ}$ 687, de 30/03/2006, que institui a Política Nacional de Promoção da Saúde. Brasília (DF): MS; 2006. (Série Pactos pela Saúde 2006 - Volume 07. Série B - Textos Básicos de Saúde)

27. Brasil. Ministério da Saúde (MS). Portaria GM/MS no 936, de 18/05/2004. Dispõe sobre a estruturação da Rede Nacional de Prevenção da Violência e Promoção da Saúde e a Implantação e Implementação de Núcleos de Prevenção à Violência em Estados e Municípios. Diário Oficial da União 2004; 20 maio.

28. Brasil. Ministério da Saúde (MS). Portaria GM/MS $n^{\circ}$ 344, de 19/02/2002, que institui o Projeto de Redução da Morbimortalidade por Acidentes de Trânsito - Mobilizando a sociedade e promovendo a saúde. 2a Edição. Brasília (DF): MS; 2002. (Série C - Projetos, Programas e Relatórios)

29. Brasil. Ministério da Saúde (MS). Secretaria de Vigilância em Saúde. Vigilância de Violências e Acidentes - VIVA 2006 e 2007. Brasília (DF): MS 2009. (Série G - Estatística e Informação em Saúde)

30. Brasil. Ministério da Saúde (MS). Secretaria de Vigilância em Saúde. Vigilância de Violências e Acidentes - VIVA 2008 e 2009. Série G - Estatística e Informação em Saúde. Brasília (DF): MS; 2010.

31. Gawryszewski VP, Silva MMA, Malta DC, Kegler SR, Mercy JA, Mascarenhas MD, Morais Neto OL. Violence-related injury in emergency departments in Brazil. Pan Am J Public Health 2008; 24(6):400-408.

32. Mascarenhas MDM, Silva MMA, Malta DC, Moura L, Macário EM, Gawryszewski VP, Neto OLM. Perfil epidemiológico dos atendimentos de emergência por violências no sistema de serviços sentinela de vigilância de violências e acidentes (VIVA). Epidemiologia e Serviços de Saúde 2009; 18(1):17-28.

33. Novoa. AM, Perez K, Borrell C. Efectividad de las intervenciones de seguridad vial basadas en la evidencia: una revision de la literatura. Gac Sanit. 2009; 23(6):553e1-14

34. Hyder AA, Allen KA, Di Pietro G, Adriazola CA, Sobel R, Larson K, Peden M. Adressing the implementation gap in global road safety: exploring features of an effective response and introducing a 10country program. Am J Public Health 2012; 102(6): 1061-1067. 